a similar effect in a Beehive Osglim lamp filled with air. ${ }^{1}$

Investigations designed to throw some light on the cause of the phenomenon have been carried on at intervals during the past two years. In the course of these, it was observed some time ago that the jumping effect was produced in an experimental tube with sealing-wax joints when the wax was heated. This suggested that the phenomenon might be caused by impurities in the filling gas. A further series of experiments led to the conclusion that the introduction of minute quantities of the vapours of certain hydrocarbons (toluene and hexane were both found effective) would produce jumps in neon-filled tubes in which the negative glow was previously quite steady.

I hope that a full account of the experiments (which showed other interesting effects of the introduction of traces of hydrocarbon vapour into neon discharge tubes) will be published in due course.

The jumping negative glow is probably related to the wavering positive column in discharge tubes containing hydrocarbons, as demonstrated recently by the General Electric Company. W. A. Leryshon. Physics Department,

London School of Medicine for Women, Oct. 16

1 Nature, Sept. 13, 1924.

Raman Spectra of Benzene and Toluene.

I HAVE during the last summer, at Macdonald Physical Laboratory, McGill University, examined the Raman spectra of benzene and toluene under the fairly high dispersion of 4-5 A. per $\mathrm{mm}$. This work has revealed that the line in the neighbourhood of $1000 \mathrm{~cm} .^{-1}$, always characteristic of the benzene ring, is complex.

In benzene there are five components : $1005 \cdot 3 \mathrm{~cm}^{-1}$

$998 \cdot 8$

$992 \cdot 2$

$983 \cdot 9$

$980 \cdot 3$

In toluene there are four frequencies in this region: $1027 \cdot 7 \mathrm{~cm}^{-1}$

$1001 \cdot 9$

$992 \cdot 2$

$968 \cdot 3$

Several other lines are observed to be complex. In addition, a number of entirely new lines are observed in toluene. A complete account of the work will appear shortly in the Canadian Journal of Research.

National Research Laboratories, LESLIE E. HowletT.

Ottawa, Sept. 28.

\section{A New and Peculiar Marine Nemertean from the} Australian Goast.

This note is to record the discovery of a rather anomalous nemertean worm from the coastal waters of New South Wales. The creature is of outstanding interest because its proboscis, that organ highly characteristic of the phylum, is apparently different altogether from any previously described for this group. In fact, we are not aware of any approximately similar protrusible organ having been recorded in any animal class.

The proboscis of the nemerteans usually consists of an introverted tube in a proboscis sheath, and it is everted like a finger of a glove that has been pulled 'outside in'. This new nemertean has also a proboscis which is retractile within a proboscis sheath, but the proboscis is branched. The branching is of the dichotomous type. By the help of the illus- tration (Fig. 1) the extraordinary nature of this organ will be realised. During eversion, which takes place almost explosively, the short main trunk first appears, then this divides and the finer and finer branches appear, but since each one of these is the result of an evagination the effect is almost indescribable. It is as if a large number of lively, wriggling, minute worms had been shot out. The tip of the animal is like a gorgon's head. The final branches, all tubular but quite thread-like, are constantly in motion, becoming now longer, now shorter.

If the stimulus has been great, there is, apparently, no possibility of the retraction of the mass and it is thrown off. But it is most interesting to watch the slow retraction which takes place when complete

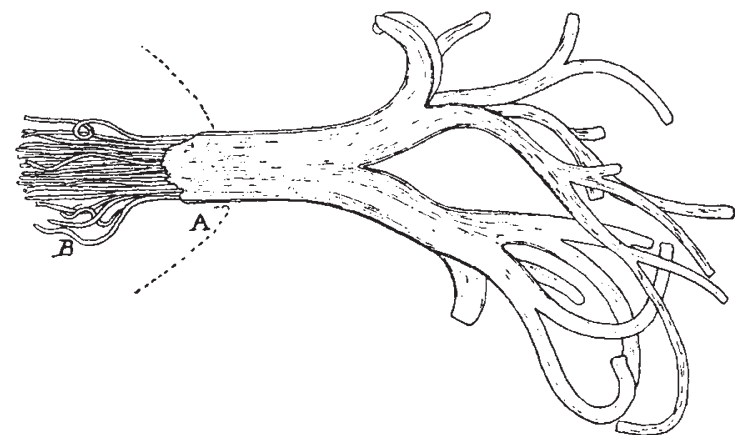

FIG. 1.-Gorgonorhynchus repens n.g. n.sp. Semi-extended proboscis torn away from the worm at $A$. At $B$ can be seen the final branches of the proboseis not yet everted.

introversion occurs. Each fine branch inverts itself from the tip-rolls inwards-the branches become shorter until their point of origin is reached, and then the junction follows suit, invaginates, and so on.

The illustration represents the result of tearing away from a worm the semi-extended proboscis. The primary and secondary branches have been everted but not the final ones, twenty or thereabouts in number, which lie within the former and still extend backwards. They have actually been exposed by the tearing away of the proboscis from the worm where its wall passes into that of the sheath.

A complete description of the anatomy of this interesting creature is being prepared. Many specimens have been found. The surprising thing is that such an anomalous form should fit in with one of the already known nemertean groups. From a study of its body wall it belongs to the Heteronemertini. We have created a new genus and species for it, Gorgonorhynchus repens, and the description here provided will serve to distinguish it from all other members of the group so far described.$$
\text { Zoology Dept. }
$$

William John Dakin.

University of Sydney, Australia. Zoology Dept.,

Mahalah G. C. Fordham.

University of Liverpool, England.

\section{Anisotropy Due to Flow in Gellulose Sols.}

IT has been known for some years that certain liquids, and sols containing anisotropic colloidal particles, which in the normal state appear isotropic, will under the influence of external forces show some of the properties of anisotropic substances. The fact that an anisotropic state can be produced in certain fluids by means of the shearing forces caused by hydrodynamic flow, is due, at least in the case of sols, to the nonspherical particles contained in them. ${ }^{1}$

$$
\text { No. 3236, VoL. 128] }
$$

